Research, part of a Special Feature on Sustainability Impact Assessment of Forest Management Alternatives in Europe

\title{
A Forest Management Map of European Forests
}

\author{
$\underline{\text { Geerten M. Hengeveld }}^{1}$, Gert-Jan Nabuurs $^{2}, \underline{\text { Markus Didion }}^{1}, \underline{\text { Isabel van den Wyngaert }}^{l}, \underline{\text { A.P.P.M. (Sandra) Clerkx }}^{1}$ \\ and Mart-Jan Schelhaas ${ }^{l}$
}

\begin{abstract}
Forest management to a large extent determines the possible services that the forest can provide. Different objectives in forest management determine the rotation length and valuation of different stages in forest succession. We present a method of mapping potential forest management at 1-km resolution to inform policy, land use modeling, and forest resource projections. The presented method calculates the suitability of a location to different forest management alternatives based on biotic, abiotic, socioeconomic, and political factors. A sensitivity analysis of the resulting map to the data sources used was performed. This showed that the results are very sensitive to some data sources. The potential use of the map and the sensitivity to the availability of data sources are discussed. An extension to the method, including regional scaling, is suggested. Data availability is the main restriction on refinement of the proposed methodology.
\end{abstract}

Key Words: Europe; forest management approach; land use mapping

\section{INTRODUCTION}

European forests provide many services to society, ranging from recreation to habitat functions, the regulation of water, erosion, and air quality, and the provisioning of wood products like timber and biomass for bioenergy (UN-ECE 2005, EEA 2007, FAO 2007, IPCC 2007, MCPFE 2007, EEA 2008, Tupek et al. 2010, Verkerk et al. 2010). Historically, European forests have been managed to increase the output of a particular service, most often the value of timber (Nabuurs 2001). However, this attention is shifting and broadening. We know that the focus of a certain management type towards one goal will affect the performance of the forest for other services. An intense timber production may, for example, have a negative effect on the habitat functions of the forest (Paillet et al. 2010). The recent interest in forests for sequestration of carbon, on the one hand, and provision of biomass for bioenergy, on the other, also illustrates the possible trade-off even within the theme of climate change mitigation (Zanchi et al. 2010).

Thus strategically, thinking about fulfilling different forest functions across the European scale becomes more and more important. The first strategic separation of functions at the European scale has already been set by the Birds and Habitat Directive and its implementation in Natura2000 sites. This gives prime attention to the nature conservation value at those sites, with possible detrimental effects on timber production. To understand such trade-offs between forest functions, a series of models has been developed to aid policy-makers and managers in optimizing management in view of the specific demands of society and the environment.

But also for land use (change) analyses of Europe, insight into the state of local forests and forest management is important. Currently, however, land use models only sparsely include differences in forest and forest management types (Schulp et al. 2008). Informed inclusion of the basic differentiation in forest management practices will improve predictions of land use, land use change, and associated carbon flux.

At the very local scale, stand-level models have been used as scientific and practical tools (Bugmann 2001, Didion et al. 2007, Pretzsch et al. 2008). For specific regions within Europe, simulation models have been developed and applied (Hasenauer et al. 2006, Pretzsch et al. 2008, Palahi et al. 2009). At the European scale, one harmonized model ([EFISCEN V3] Nabuurs et al. 2003, Schelhaas et al. 2007) is now used to support the international negotiations on the role of forests in European commitments to reduce greenhouse gases (Bottcher et al. 2012). Although the current EFISCEN has a large number of forest types, management regimes, and regionally specific data, it cannot capture the huge ecological diversity across Europe, nor the huge management diversity.

To increase spatial resolution of forest representation in Europe, Brus et al. (2012) produced a tree species forest map of Europe at 1-km resolution, which is an important step when desiring to improve forest resource and management analyses across Europe. However, it is impossible to manually define the management in each of the 5.5 million pixels.

We present a conceptual framework and first tests to stratify forest management across European forests using the tree species map and other abiotic constraints. The approach is to classify management throughout Europe into broad groups with similar objectives and strategies. These broad management approaches can then be further detailed into silvicultural operations according to regional or local circumstances, traditions, and management regulations. Duncker et al. (2012) present such a broad approach, which defines five forest management approaches (FMAs) along a

${ }^{1}$ ALTERRA - Wageningen UR, ${ }^{2}$ European Forest Institute 
gradient of production intensity. Our objective is to conceptualize and test a detailed map that reflects the local constraints that differentiate and spatially distribute broad forest management approaches in Europe using the framework of Duncker et al. (2012).

\section{METHODS}

The basis for the forest management map is the European tree species map (Brus et al. 2012). This map defines the probability of occurrence for 20 species groups at a $1-\mathrm{km}$ resolution. For all species groups with a probability of occurrence greater than $1 \%$, the probability of occurrence was taken to represent the area of a forest stand dominated by the species group. For each of these stands, we defined the most suitable forest management alternative based on eight factors. The most suitable forest management alternative at the pixel level was then defined by the forest management alternative that was most suitable in the largest area in that $1 \mathrm{x} 1 \mathrm{~km}$ pixel.

\section{Forest management approach framework}

Duncker et al. (2012) present a framework for classifying different FMAs along a gradient of intensity of intervention with the natural processes in a forest. They distinguish five FMAs: FMA I: unmanaged nature reserves; FMA II: closeto-nature forestry; FMA III: combined objective forestry; FMA IV: intensive even-aged; and FMA V: short rotation forestry (Table 1). These FMAs differ in both objective and allowed silvicultural operations. For a full elaboration, we refer to Duncker et al. (2012). These FMAs provide a crosscontinental framework for defining management options.

Table 1. Description of forest management approaches (FMAs), following Duncker et al. (2012).

\begin{tabular}{cll}
\hline \hline FMA & Description & Intensity of management \\
\hline I & Nature reserve & No intervention \\
II & Close-to-nature & Interventions mimic natural processes \\
III & Combined objective & Limited interventions \\
& forestry & \\
IV & Even-aged forestry & Interventions follow production goals \\
V & Short rotation & Intensive management for maximum \\
& forestry & biomass \\
\hline
\end{tabular}

\section{Conceptual framework}

The decision by a forest manager about how to manage a specific forest stand is influenced by many different factors. They can be divided in four categories: biotic, abiotic, socioeconomic, and political. The biotic component includes stand characteristics like stand area, tree species composition, and stand structure. Abiotic conditions include site factors like climate, topography, and soil. Socioeconomic conditions include the wood market, extraction costs, transport opportunities, specific goals or interests of the forest owner, subsidies, and recreation pressure. Political factors include policies, regulations, and restrictions on forest operations issued at various levels of organization. While the stand characteristics may partially influence the decision of an owner about what to do and what to strive for, at the same time they reflect past decisions and operations and might reveal some of the intentions of the forest owner.

We assumed that we could approximate the forest owner's choice of an FMA by combining underlying drivers in the four categories. For each of these categories, we identified at least one European-wide spatially explicit data set that corresponds to a factor that will influence the owner's decision. In total, we selected eight factors based on availability and suitability (Fig. 1). For the biotic conditions, we used the applicability of the dominant species (a) in each stand for a given FMA (Table 2). To incorporate regional differences in species use, these applicabilities were assigned based on four biogeographical regions (b). For the abiotic conditions, we selected the slope (c) as the important decision variable. The slope sets important constraints on the applicability of intensive silvicultural operations (Sterba et al. 2000). Two types of proximity maps (Verburg et al. 2008) were used as a proxy for socioeconomic conditions. Small-scale proximity (d), defined as distance to cities of at least 25,000 inhabitants, represented recreation pressure. The large-scale proximity (e), i.e., to cities of at least 750,000 inhabitants, was considered a proxy for distance to major wood-working industries (Sterba et al. 2000, Beach et al. 2005). Additionally, we used the percentage of the pixel covered by forest (f) (Schuck et al. 2002) and stand area (g) (Brus et al. 2012) as a proxy for the economic feasibility of intensive forestry (Beach et al. 2005). For the political category, we used a map with the Natura2000 sites (h) (European Commission, DG Environment, 2009, Natura2000 database, version July 2009) as an indication of where operations will be more likely to be influenced by conservation policies (Verkerk and Lindner 2008).

\section{Calculation method}

For each stand, the local suitability for being managed according to an FMA of type $j\left(S\left[F M A_{j}\right]\right)$ was calculated using the following algorithm:

$$
S\left(F M A_{j}\right)=p_{F M A_{j x}} \frac{\sum_{i} \alpha_{i j} \times F_{i j}\left(g_{i}\right)}{\sum_{i} \alpha_{i j}}
$$

where $p_{F M A, j x}$ is the applicability of $F M A_{j}$ for species $x$ (Table $2), \alpha_{i j}$ is a weighting factor indicating the importance of factor $g_{i}$ for $F M A_{j}\left(\right.$ Table 3 ), and $F_{i j}$ is the response function of $F M A_{j}$ to factor $g_{i}$, where:

$$
F_{i j} \in[-0.5,0.5]
$$


Table 2. The applicability of forest management approaches (pFMA) for the different species separated by biogeographic regions. FMA I: nature reserve, II: close-to-nature, III: combined objective, IV: even-aged forestry, V: short rotation. Applicability ranges from small (1) to large (4). Based on author judgment.

\begin{tabular}{|c|c|c|c|c|c|c|}
\hline \multirow[b]{2}{*}{ Species } & \multirow[b]{2}{*}{ Biogeographical region } & \multicolumn{5}{|c|}{ FMA } \\
\hline & & $\mathrm{I}$ & II & III & IV & $\mathrm{V}$ \\
\hline \multirow[t]{4}{*}{ Abies spp. } & Atlantic & 0 & 0 & 4 & 4 & 1 \\
\hline & Boreal & 0 & 0 & 3 & 4 & 1 \\
\hline & Continental & 4 & 4 & 3 & 1 & 0 \\
\hline & Mediterranean & 0 & 0 & 2 & 3 & 1 \\
\hline \multirow[t]{3}{*}{ Larix spp. } & Atlantic and Boreal & 0 & 1 & 4 & 4 & 3 \\
\hline & Continental & 1 & 1 & 4 & 4 & 1 \\
\hline & Mediterranean & 0 & 1 & 3 & 2 & 0 \\
\hline \multirow[t]{4}{*}{ Picea spp. } & Atlantic & 0 & 1 & 3 & 4 & 4 \\
\hline & Boreal & 2 & 3 & 4 & 3 & 1 \\
\hline & Continental & 2 & 3 & 4 & 4 & 2 \\
\hline & Mediterranean & 1 & 1 & 4 & 4 & 1 \\
\hline \multirow[t]{2}{*}{ Pinus pinaster } & Atlantic & 0 & 0 & 3 & 4 & 1 \\
\hline & Mediterranean & 1 & 2 & 4 & 4 & 4 \\
\hline \multirow[t]{3}{*}{ Pinus sylvestris } & Atlantic & 3 & 4 & 4 & 4 & 4 \\
\hline & Boreal and Mediterranean & 2 & 2 & 4 & 4 & 0 \\
\hline & Continental & 3 & 4 & 4 & 4 & 0 \\
\hline \multirow{3}{*}{ Other Pinus spp. } & Atlantic and Boreal & 0 & 0 & 4 & 4 & 3 \\
\hline & Continental & 0 & 1 & 4 & 3 & 2 \\
\hline & Mediterranean & 2 & 2 & 2 & 2 & 0 \\
\hline \multirow{3}{*}{ Pseudotsuga spp. } & Atlantic & 0 & 1 & 4 & 4 & 3 \\
\hline & Continental & 0 & 1 & 4 & 4 & 1 \\
\hline & Mediterranean & 0 & 0 & 3 & 4 & 4 \\
\hline Other conifers & All & 2 & 2 & 2 & 2 & 2 \\
\hline \multirow[t]{4}{*}{ Alnus spp. } & Atlantic & 4 & 4 & 2 & 2 & 1 \\
\hline & Boreal & 2 & 2 & 3 & 3 & 1 \\
\hline & Continental & 3 & 3 & 3 & 2 & 0 \\
\hline & Mediterranean & 4 & 4 & 1 & 1 & 0 \\
\hline \multirow[t]{4}{*}{ Betula spp. } & Atlantic & 4 & 4 & 2 & 0 & 0 \\
\hline & Boreal & 3 & 3 & 3 & 2 & 0 \\
\hline & Continental & 2 & 2 & 3 & 2 & 0 \\
\hline & Mediterranean & 4 & 4 & 4 & 1 & 0 \\
\hline \multirow[t]{2}{*}{ Carpinus spp. } & Atlantic and Continental & 4 & 4 & 2 & 0 & 0 \\
\hline & Mediterranean & 4 & 4 & 3 & 1 & 0 \\
\hline \multirow[t]{3}{*}{ Castanea spp. } & Atlantic & 0 & 1 & 4 & 4 & 0 \\
\hline & Continental & 0 & 1 & 2 & 2 & 0 \\
\hline & Mediterranean & 4 & 4 & 3 & 2 & 0 \\
\hline \multirow[t]{2}{*}{ Eucalyptus spp. } & Atlantic & 0 & 0 & 1 & 4 & 4 \\
\hline & Mediterranean & 0 & 0 & 3 & 4 & 4 \\
\hline \multirow[t]{3}{*}{ Fagus spp. } & Atlantic & 4 & 4 & 4 & 3 & 0 \\
\hline & Continental & 4 & 4 & 4 & 4 & 0 \\
\hline & Mediterranean & 4 & 4 & 4 & 3 & 0 \\
\hline \multirow[t]{4}{*}{ Fraxinus spp. } & Atlantic & 2 & 2 & 2 & 2 & 2 \\
\hline & Boreal & 4 & 4 & 3 & 1 & 0 \\
\hline & Continental & 4 & 4 & 4 & 1 & 0 \\
\hline & Mediterranean & 4 & 4 & 4 & 2 & 0 \\
\hline \multirow[t]{2}{*}{ Populus spp. } & Atlantic and Continental and Mediterranean & 4 & 4 & 4 & 4 & 4 \\
\hline & Boreal & 2 & 2 & 0 & 0 & 2 \\
\hline Quercus robur and $Q$. petraea & Atlantic & 4 & 4 & 4 & 1 & 0 \\
\hline & Continental & 4 & 4 & 4 & 3 & 2 \\
\hline & Mediterranean & 4 & 4 & 4 & 3 & 0 \\
\hline Other Quercus spp. & Atlantic & 0 & 1 & 3 & 2 & 0 \\
\hline & Continental & 4 & 4 & 4 & 4 & 2 \\
\hline & Mediterranean & 4 & 4 & 4 & 3 & 0 \\
\hline
\end{tabular}




\begin{tabular}{|c|c|c|c|c|c|c|}
\hline \multirow[t]{3}{*}{ Robinia spp. } & Atlantic & 0 & 0 & 4 & 4 & 3 \\
\hline & Continental & 0 & 1 & 4 & 4 & 3 \\
\hline & Mediterranean & 0 & 1 & 4 & 4 & 3 \\
\hline Other broad-leaved & All & 2 & 2 & 2 & 2 & 2 \\
\hline \multirow[t]{3}{*}{ Multiple species } & Atlantic and Mediterranean & 4 & 4 & 2 & 1 & 0 \\
\hline & Boreal & 4 & 4 & 3 & 2 & 0 \\
\hline & Continental & 4 & 4 & 3 & 1 & 0 \\
\hline
\end{tabular}

Table 3. Qualitative weighting factors $\alpha$ (Eq. 1) for effect of a factor on suitability. + indicates a minor positive effect, indicates a minor negative effect, and ++ indicates a major positive effect. For step functions, the cut-off point is given in brackets. FMA I: nature reserve, II: close-to-nature, III: combined objective, IV: even-aged forestry, V: short rotation.

\begin{tabular}{|c|c|c|c|c|c|}
\hline & $\mathrm{I}$ & II & III & IV & $\mathrm{V}$ \\
\hline c slope & & & & $-(>25)$ & $-(>10)$ \\
\hline d proximity 1 & & ++ & + & ++ & \\
\hline e proximity 2 & - & & & + & + \\
\hline f forest cover & & & & ++ & + \\
\hline g stand area (SA) & & - & & + & + \\
\hline h Natura2000 & $+(>\mathrm{SA})$ & $+(>\mathrm{SA})$ & & & $-(<\mathrm{SA})$ \\
\hline
\end{tabular}

In principle, $F_{i j}$ can take any form, and is flexible to either categorical or continuous data.

In Eq. 1, $j$ ranges from 1 to 5, corresponding to the five FMAs defined by Duncker et al. (2012). Species $x$ corresponds to the 20 species groups defined in the European tree species map (Brus et al. 2012; see Table 2 for tree species groups). Factor $g_{i}$ corresponds to the six data sets, $\mathrm{c}-\mathrm{h}$, mentioned in Methods: Conceptual framework. Each $g_{i}$ was scaled using either linear (proximity, the percentage of forest in the pixel, and the area of the stand) or threshold response functions $F_{i j}\left(\mathrm{~g}_{i}\right)$ to values between -0.5 and 0.5 . Specific weighting factors $\left(a_{i j}\right)$ and response functions $\left(F_{i j}\left(\mathrm{~g}_{i}\right)\right)$ are explained in Methods: Factor description.

Using this algorithm, each stand could be assigned a suitability for being managed according to a given FMA. An FMA was assigned to the stand according to the highest suitability. For the pixel, the FMA type covering the largest area (summed over all stands in the pixel) was taken.

\section{Factor description}

The applicability of an FMA to a species $\left(p_{F M A, j x}\right)$ was expressed on a scale ranging from 1 (hardly applicable) to 4 (highly applicable) based on the authors' judgment. Indigenous species are likely to appear in nature reserves (FMA I) and close-to-nature forestry (FMA II). Species able to provide timber of good quality and with a reasonable production are likely to be associated with combined objective management (FMA III) and even-aged forestry (FMA IV). High-yielding species are likely to be associated with short rotation forestry (FMA V). Productivity and being indigenous differs by species within Europe. Therefore, we regionalized the values for $p_{F M A, j x}$ according to four broad biogeographic regions (Fig. 1b), as shown in Table 2.

The assignment of response functions and weighting factors for each of the other data sets is presented in Table 3 and was based on the authors' judgment. Effects can be strongly positive or negative, weakly positive or negative, or neutral. If no effect was assumed, this was due to either no expected effect or to multiple trends in opposite directions. Strong and weak effects were implemented by assigning weighting factor $\alpha$ arbitrary values of 9 and 2, respectively.

We expected slope to negatively affect the suitability of the productive FMAs (IV and V) because steeper slopes are susceptible to soil erosion under intensive management. Suitability was therefore reduced for slopes greater than $10 \%$ for FMA V and for slopes greater than $25 \%$ for FMA IV (EEA 2007).

Proximity to small towns was considered to have a major positive effect on the suitability of both FMA II and FMA IV and a minor positive effect on the suitability of FMA III. Proximity to either small or large cities had a positive effect on the nature-recreation value that is important for FMA II, and on the multiple objectives being targeted in FMA III, and short distances to labor will enhance the value of a forest stand for timber production. The proximity to large cities, considered as a proxy for distance to major industry, was assumed to have a positive effect on suitability for biomass production in FMA V, whereas suitability for FMA I, which is free of human intervention, was considered to be negatively influenced by proximity to large urban areas.

The production of timber and biomass can be done most efficiently in large forest complexes and/or in large stands. Therefore, suitability of both FMA IV and V were assumed to increase with forest cover within the pixel and with the size of the stand. Small stands are especially suitable for FMA II, in which the production objective is restricted by management objectives for recreation and biodiversity purposes.

In Natura2000 areas, the main function of forests is the protection of biodiversity (European Commission, DG Environment, 2009, Natura2000 database, version July 2009, available only within EU countries). Forests within Natura2000 areas were therefore considered to have a higher 
Fig. 1. Flow chart for compilation of the map of forest management approaches. Schematic representation of how the different (GIS-) data sets were combined using the parameter values of Tables 1 and 2 in Equation 1. Data sets are (a) tree species distribution map, (b) biogeographic regions, (c) slope, (d) proximity to towns larger than 25,000 inhabitants, (e) proximity to cities larger than 750,000 inhabitants, (f) forest cover, (g) stand area derived from the tree species map of Europe, and (h) Natura2000 regions. Arrow (i) combines the biogeographic and species information with the regional species suitability to form pFMA in Equation $1(\mathrm{k})$. Arrow $(\mathrm{j})$ combines the data sets $(\mathrm{c}-\mathrm{h})$ on factors $(\mathrm{gi})$ with the weighting factors $(\alpha)$ from Table 2 in Equation 1. Equation $1(\mathrm{k})$ combines the different data sets into a suitability measure for each forest management approach in each stand. Arrow (l) combines these suitabilities into a map of the most suitable forest management approach per square kilometer $(\mathrm{m})$.

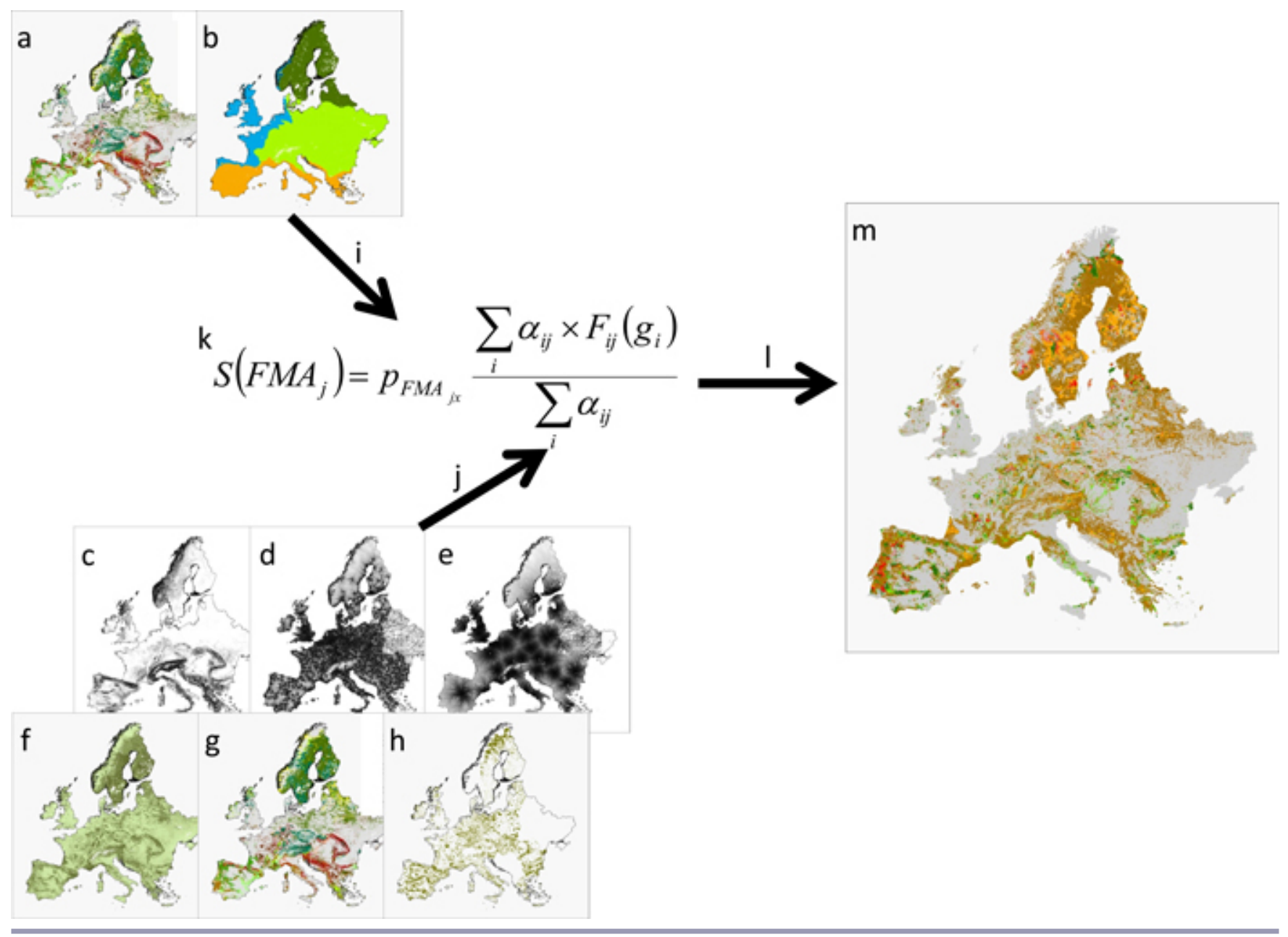

likelihood of having FMA I and II, and a lower likelihood of the production-oriented FMA IV and V. Stands smaller than the Natura2000 areas in a pixel were assigned higher suitability for the nature-oriented FMAs I and II.

\section{Sensitivity analysis}

A sensitivity analysis was performed to test the effect of the different layers on the final FMA assignment. To this end, the map was recalculated six times, each time omitting one map layer. The sensitivity of an FMA type to a map layer was then expressed as the percentage of pixels that changed to another FMA type relative to the original map.

\section{Validation}

In order to assess the accuracy of the resulting FMA map, we used two approaches. In the first approach, we assigned FMAs to the plots based on the national forest inventory of the Netherlands (Dirkse et al. 2003; Daamen, 2004, personal communication) and the regional inventory of Umbria (Italy) (Colle et al. 2006; Teobaldelli, 2007, personal communication). This data set comprises 2,659 plots in Umbria and 2,551 plots in the Netherlands, distributed evenly over the two sample areas. The reclassification of the original management categories into FMAs is given in Table 4. The 
Fig. 2. Dominant forest management approach (FMA) in Europe. Distribution of FMAs according to dominant suitability per $1-\mathrm{km}^{2}$ pixel, using parameters from Table 2. Results are shown for pixels with more than $25 \%$ forest cover. For a definition of dominant suitability, see text.

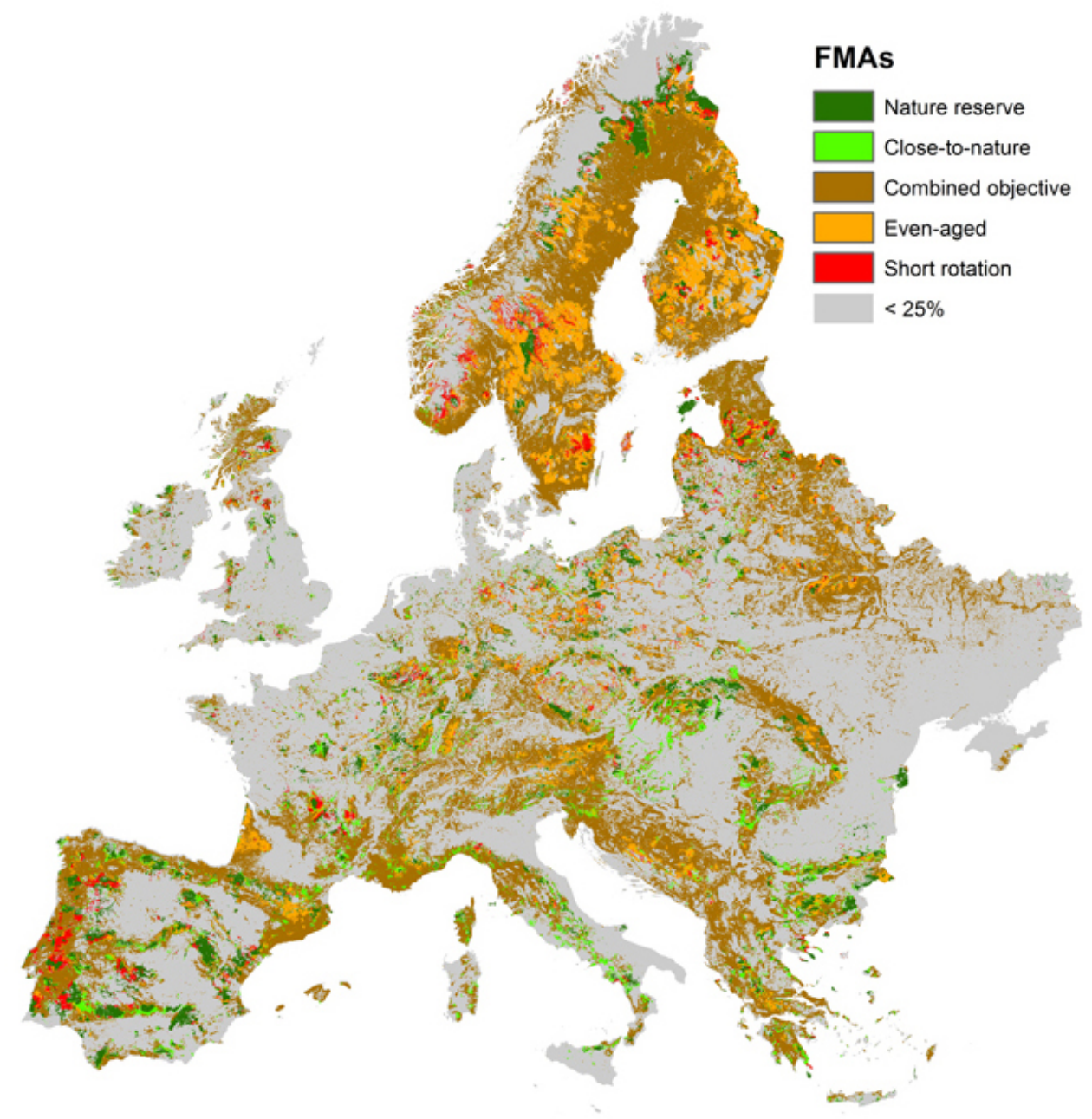

average suitability of the observed FMAs at the observed location was then compared to the average suitability of the FMA in the region.

In the second approach, we compared the total area classified in the different FMAs for each country with the areas reported under the Ministerial Conference on the Protection of Forests in Europe (MCPFE) class 1 (MCPFE 2007). Following the descriptions of the FMAs presented by Duncker et al. (2012), subclasses 1.1 and 1.2 were categorized as FMA I, and subclass 1.3 was categorized as FMA II.

\section{RESULTS}

The assigned forest management approaches for the whole of Europe are summarized in Table 5, and the number of stands with maximum suitability for each forest management approach are summed. Figure 2 shows the dominant FMA mapped per $1 \mathrm{~km}^{2}$ pixel. Access to the detailed map and the suitability scores for each pixel is given through online resource 1. These results are dominated by FMA III (64.7\% of the stands), which is an intermediate intensity management that describes forest management with a production-oriented objective but which also allows for alternative objectives that reduce production. Eighteen percent of the stands were assigned to FMA II, which is forest with a close-to-nature management regime, while the other FMAs were assigned to less than $10 \%$ of the stands.

Potentially, the various FMAs occur throughout Europe. There are no large-scale trends differentiating management intensity across Europe; this is quite well in line with the forest characterization of Europe (Farrell et al. 2000, MCPFE 2007). 
Table 4. Classification of forest management descriptions to forest management approaches (FMAs). (Forest management descriptions from national inventory plots. FMAs I: naturereserve; II: close-to-nature; III: combined objective; IV: evenaged forestry; V: short rotation)

\begin{tabular}{llc}
\hline \hline Region & Forest management description & FMA \\
\hline Umbria & Direct protection & I \\
& Ecological & II \\
& Indirect protection & II \\
& Nonwood production & II \\
& Tourist-recreational & III \\
& Wood production & IV \\
Netherlands & Onbeheerd (unmanaged) & I \\
& Spontaan bos (spontaneous forest) & I \\
& Struweel < 8 m (thicket) & I \\
& Omvorming (transition) & II \\
& Recreatiebos (recreation forest) & II \\
& Houtwal (wooded bank) & III \\
& Laan (avenue) & III \\
& Landgoedbos (estate forest) & III \\
& Landschap (landscape) & III \\
& Ongelijkjarig (uneven-aged) & III \\
& Overige niet-recreatieve bosfunctie (other & III \\
& nonrecreative function) & \\
Singel & III \\
Boombos & IV \\
Gelijkjarig (even-aged) & IV \\
Hakhout (coppice) & IV \\
Schermbos (protective forest) & IV \\
Griend-energie (short rotation coppice) & V \\
\hline & & \\
& &
\end{tabular}

However, some regional characterization is apparent. Scandinavia is characterized by large areas that are most suitable for FMA IV, intensive even-aged forest, with relatively large patches suitable for FMA V (short rotation forestry) and FMA I (unmanaged forests). The latter are generally restricted to high altitude and high latitude forests. The western central European countries show a highly fragmented forest landscape with a mix of all FMAs. The regions of Aquitaine, France and the north of Catalonia, Spain are characterized by a relatively large area that is suitable for FMA IV, intensive even-aged forest, while Portugal is characterized by patches of high suitability for short rotation forestry types in a landscape dominated by combined objective forests. Spain shows potential for some large reserves (FMA I-dominated areas). Towards the east in the Baltic states and Belarus, combined objective management dominates, with scattered areas suitable for short rotation forestry. Towards the Carpathians, combined objective management dominates as well, with scattered areas with high suitability for reserves. This is also the case in Bulgaria, Greece, and Italy. The western Balkans are also dominated by combined objective forests, with some areas suitable for intensive even-aged forests.
Table 5. Number of stands assigned to each forest management approach (FMA) for the whole of Europe before aggregating to pixel level. (FMA I: nature reserve; II: close-to-nature; III: combined objective; IV: even-aged forestry; V: short rotation)

\begin{tabular}{ccc}
\hline \hline FMA & Number of stands & \% of stands \\
\hline I & $1,620,334$ & 8.2 \\
II & $3,599,386$ & 18.3 \\
III & $12,757,591$ & 64.7 \\
IV & $1,126,088$ & 5.7 \\
V & 613,308 & 3.1 \\
\hline
\end{tabular}

The sensitivity to each of the input GIS layers was expressed as the fraction of pixels that changed FMA due to the removal of one layer from the calculations (Table 6). Overall sensitivity to slope was low, whereas sensitivity to small-scale proximity was $79 \%$, and sensitivity to stand area was $74 \%$. Within each FMA type, sensitivity was greatest for different layers: Natura2000 and stand area for FMA I, large-scale proximity for FMA II, small-scale proximity and stand area for FMA III, forest cover for FMA IV, and small-scale proximity for FMA $\mathrm{V}$. The weighting factor $\alpha$ was of importance for the assignment of FMA IV and to a lesser extent FMA I and FMA $\mathrm{V}$. The suitability of the species for an FMA was important mostly for FMA IV and FMA V.

Table 6. Sensitivity of the map to data sources. Fraction of pixels that changed dominant forest management approach (FMA) after removal of the different data sources $(\mathrm{a}-\mathrm{h})$ and application of equal weights to minor and major effects. (FMA I: nature reserve; II: close-to-nature; III: combined objective; IV: even-aged forestry; V: short rotation)

\begin{tabular}{llcccccc}
\hline \hline & & All & I & II & III & IV & V \\
\hline & $\alpha$ & 0.13 & 0.49 & 0.03 & 0.03 & 0.75 & 0.48 \\
$\mathrm{a} * \mathrm{~b}$ & species * biogeo & 0.10 & 0.02 & 0.11 & 0.09 & 0.25 & 0.37 \\
$\mathrm{c}$ & slope & 0.01 & 0.01 & 0.01 & 0.01 & 0.01 & 0.05 \\
$\mathrm{~d}$ & proximity 1 & 0.79 & 0.23 & 0.35 & 1.00 & 0.00 & 0.97 \\
$\mathrm{e}$ & proximity 2 & 0.13 & 0.22 & 0.62 & 0.04 & 0.11 & 0.09 \\
$\mathrm{f}$ & forest cover & 0.07 & 0.01 & 0.02 & 0.00 & 0.96 & 0.05 \\
$\mathrm{~g}$ & stand area & 0.74 & 0.40 & 0.33 & 0.93 & 0.15 & 0.04 \\
$\mathrm{~h}$ & Natura2000 & 0.36 & 0.40 & 0.30 & 0.35 & 0.30 & 0.78 \\
\hline
\end{tabular}

Two attempts at the validation of calculated suitabilities were undertaken. First, the calculated suitability for the observed forest management at plot locations in regions in Europe was compared to the average suitability in the region. The results are shown in Table 7. Compared to the distribution of observed FMAs at the plot locations, the distribution of suitability for FMAs at the stands shifted downward, with the most frequently observed FMA, FMA IV (even-aged management, $75 \%$ of the observations for Umbria and $67.5 \%$ in the Netherlands) shifting to a prediction that FMA III is the most suitable (multi-functional management, $64.9 \%$ of the 
Table 7. Distribution and suitability index of observed forest management approaches (FMAs) in Umbria and the Netherlands. Distribution is given for plots (observations) and stands (predictions), both in absolute numbers and in percentages. Calculated suitability indices for the recorded FMA at the plot data locations (Suitability of plots) are compared to average suitability of this FMA within the region (Suitability all). (FMA I: nature reserve; II: close-to-nature; III: combined objective; IV: even-aged forestry; V: short rotation)

\begin{tabular}{|c|c|c|c|c|c|c|c|}
\hline Region & FMA & Number of plots & $\%$ of plots & Number of stands & $\%$ of stands & $\begin{array}{l}\text { Suitability of } \\
\text { plots }\end{array}$ & Suitability all \\
\hline \multirow[t]{5}{*}{ Umbria } & I & 25 & 0.9 & 2,407 & 11.0 & -0.03 & -0.09 \\
\hline & II & & 0.0 & 3,696 & 16.9 & & \\
\hline & III & 636 & 23.9 & 14,177 & 64.9 & 0.13 & 0.18 \\
\hline & IV & 1,995 & 75.1 & 1,052 & 4.8 & 0.03 & 0 \\
\hline & $\mathrm{V}$ & & 0.0 & 512 & 2.3 & & \\
\hline \multirow{5}{*}{ Netherlands } & I & 28 & 1.1 & 1,983 & 3.4 & 0.05 & -0.09 \\
\hline & II & 190 & 7.6 & 15,272 & 26.5 & 0.2 & 0.21 \\
\hline & III & 586 & 23.6 & 39,549 & 68.7 & 0.28 & 0.25 \\
\hline & IV & 1,677 & 67.5 & 554 & 1.0 & 0.04 & -0.02 \\
\hline & $\mathrm{V}$ & 5 & 0.2 & 246 & 0.4 & -0.07 & -0.05 \\
\hline
\end{tabular}

predictions for Umbria and $68.7 \%$ in the Netherlands). A forest management approach was, on average, not observed on locations with higher predicted suitability for this approach.

Secondly, the areas reported under MCPFE class 1 were compared to the areas predicted to be most suitable for FMA I and II (Fig. 3). MCPFE classes 1.1 and 1.2 were categorized as FMA I, and MCPFE class 1.3 was categorized as FMA II. The maps in Figure 3 show that there were marked regional differences between predicted area of each FMA and the area reported under MCPFE class 1. For some countries (e.g., Finland, Netherlands, Switzerland), the predictions seemed to match reported areas, whereas for other countries (e.g., France, Germany, and Italy), the predictions did not match the reported areas at all. In most cases where predictions did not match, there was a strong overprediction for both FMA I and II. Marked exceptions were the area predicted for FMA II in Germany, and the area predicted for FMA I in Italy. In these cases, the areas reported were far larger than the areas predicted.

\section{DISCUSSION}

We have presented a conceptual method for assigning forest management approaches to forests across Europe. Forest management approaches are a grouping of forest management systems that allows for cross-region comparison of the effect of forest management (Duncker et al. 2012). The strategic management choices of where to conserve nature and where to produce wood are often done locally at the management unit or nationally at assigning reserve areas. The mapping of potential management at the European scale has never been done. The method presented here, and the results are a first step in such a direction.

The conceptual method calculates the local suitability for each FMA based on local GIS information. The FMA for which the local suitability is highest is then projected as the local FMA.
This projection is thus subject to both the assumption that suitability is correctly calculated and local forest owners would manage according to the highest suitability.

The forest management assigned is determined by tree species, slope, percentage of forest, proximity to cities, and Natura2000 areas. The sensitivity of the map to these different factors is diverse. Slope seems to have little added effect on the results, whereas proximity to small villages has a large effect. This will be caused partly by interactions between the different factors-e.g., those areas influenced by slope could be part of Natura2000 areas, which causes them to maintain their original classification. The major effect of the proximity to small villages is that suitability for FMA III, the most common FMA in the result, is determined only by this factor. Thus, removing this factor majorly changes the suitability of almost all pixels that were assigned this FMA. Most FMAs are affected by several factors and can even be majorly affected by the exclusion of layers that do not directly determine their suitability (e.g., FMA III is affected by the exclusion of stand area, thus causing a large move from FMA III to FMA II).

Some of the factors used are rough proxies, and could, in the future, be replaced by better data sources. For example, the proximity to large cities could be replaced by the actual location and size of pulp mills, paper mills, and sawmills. However, existing data sets at the European scale are not complete (http://www.sawmilldatabase.com/). Data availability is also a problem for other potentially important data sources, such as detailed maps on forest ownership, actual strict reserves maps, and potential productivity per species. Most important in this is the lack of productivity-related factors (Beach et al. 2005) in the calculation of the suitability, because historically, less productive sites were set aside more easily for nonproductive forest management targets. Other improvements could be the inclusion of stand characteristics, 
Fig. 3. Comparing forest management approach (FMA) I and II with Ministerial Conference on the Protection of Forests in Europe (MCPFE) class 1. (a) For each country, the summed area reported under MCPFE 1.1 and 1.2 is shown (white bar) next to the area predicted most suitable for FMA I (black bar). (b) For each country, the area reported under MCPFE 1.3 is shown (white bar) next to the area predicted most suitable for FMA II (black bar). For Spain, no forest area according to the MCPFE classification is reported (MCPFE 2007). Numbers in the legend show the area $\left(\mathrm{km}^{2}\right)$ represented by the bars.
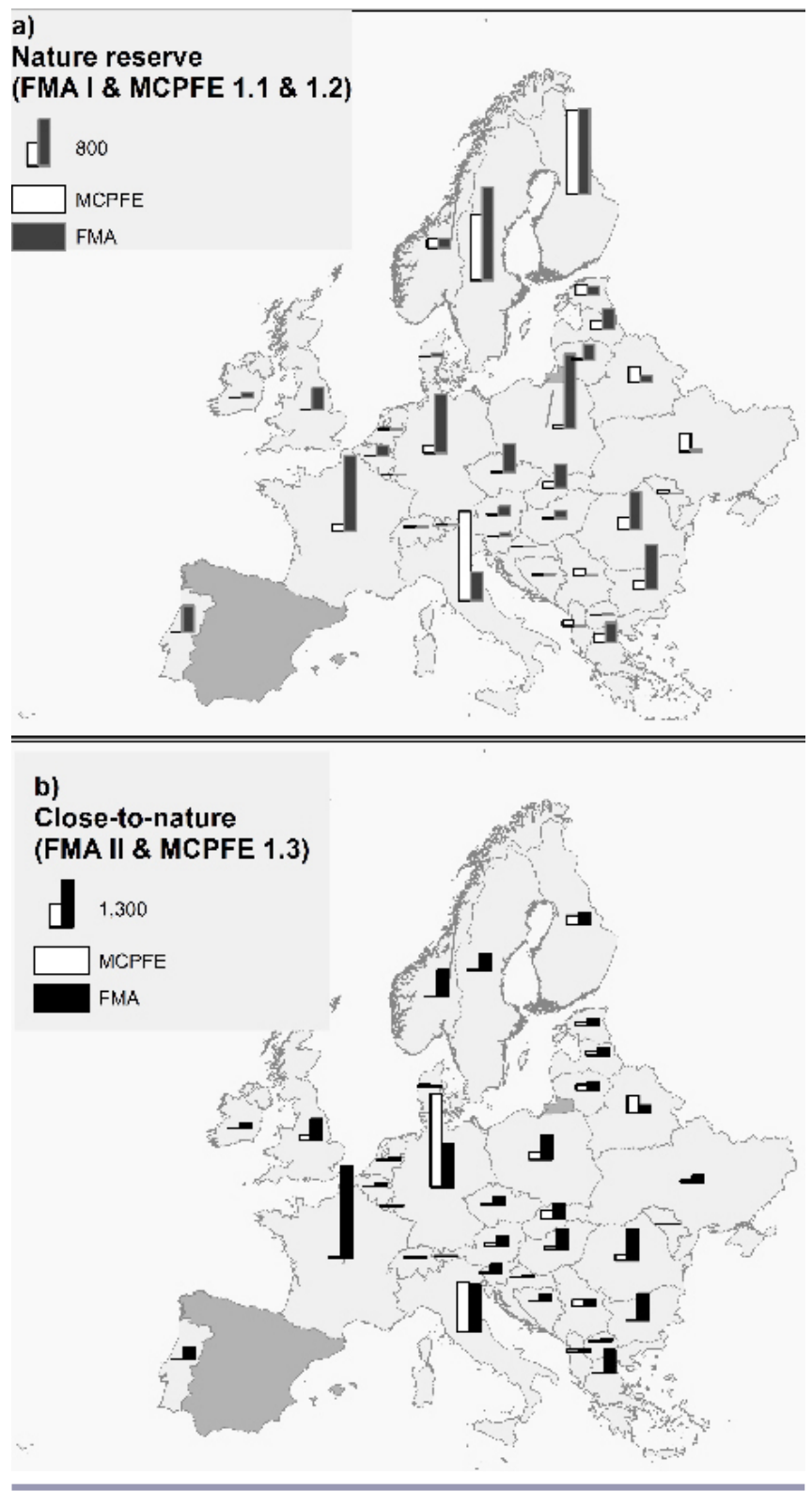

such as the number of species or the range of diameter classes in the stand, and national requirements of wood supply or production, which would set target total areas for the more productive forest management approaches, for example.

For the Netherlands and Umbria, this map is compared to a reference data set of national forest inventory plots. The results indicate that the predicted FMAs are on average about one class lower than the actual FMA as classified on the plot data: FMA IV is highly common in the observations, whereas FMA III is overrepresented in the predictions. Interpretation of this difference is difficult. First of all, the classification of actual management is rather uncertain. As shown by Duncker et al. (2012), one forest can show characteristics of different FMAs at the same time for a range of different assessment criteria. Assignment of management types is usually based on only one field observation and on limited criteria (appearance of the forest and signs of recent harvest activities [Dirkse 2003]). Future reassessment of permanent sample plots might lead to more precise assignment of actual management. The subsequent aggregation into FMAs is subjective as well, thus leading to additional uncertainty.

Apart from the classification uncertainty, this test compares suitability with actual management. It is thus a combined test of the quality of the suitability calculation and the rationality of the forest manager. Regional circumstances and owner preferences might well lead to other management goals than expected based on the rationale behind the suitability calculation. For a better validation, more detailed data sets on actual management should be available, and preferably would be continuous over large regions. Ideally, this information should then be combined with independent expert estimates of optimal FMA and/or information on regional policies, owner preferences, and other important influences. However, it is exactly the lack of such information that led to the construction of the approach presented here.

The areas reported to the MCPFE were used for comparison at the national level. Of the areas reported under MCPFE class 1, the subcategories most closely matching FMA I and FMA II were used. For most countries, the areas reported are smaller than the areas predicted to be most suitable. This would indicate an underutilization of the potential for nature conservation in many counties. To fit the model predictions to such regional statistics, the final areas predicted can be adjusted through scaling (e.g., Tröltzsch et al. 2009).

Constraints on the choice for an FMA through, for example, the demand for certain forest services or owner preferences is not accounted for in the calculation of the suitability. Iterative scaling methods (Tröltzsch et al. 2009) can be used to adjust the model predictions to regional demand for certain FMAs. In such a scaling procedure, the total suitability of each FMA in each region is adjusted to meet the target area for each FMA, while the variation within the region for each suitability is maintained. 
Sources for regional FMA distributions can be statistics reported by national forest inventories or indirect information because the areas reported under the MCPFE classification, the national or regional timber yield, and regional information on ownership of forests can potentially be translated into regional FMA distributions. Currently, integrated information at the European scale is, however, lacking (Schelhaas et al. 2003).

A European map of forest management approaches as presented has several applications. The differentiation of forest land in areas with different management goals can inform policy-makers on the suitability of European forests for different goals. Taken more in detail, attempts can be made to explicitly map ecosystem services that are likely to be coupled with specific FMA types in combination with other GIS information. Differences in forest management objectives imply different valuation of the forested lands under these FMAs. This information can inform land use and land cover models on the differences in transition rates from specific FMA types to nonforested land use types, for example, to ensure continuity of protected forests or to align land use change with rotation cycles in short rotation or even-aged forestry.

Combined with information on tree species (Brus et al. 2012) and biomass (Gallaun et al. 2010), this map provides essential information for the development and application of highresolution forest resource models, thus enabling projections on the potential for forests to deliver ecosystem services as carbon storage, timber, and recreation more accurately than can be done using current European models (Schelhaas et al. 2003).

Given the limited availability of data on forest management practices in specific stands at the European scale, we presented a method to assign forest management approaches to a highresolution forest stand map in order to facilitate forest resource and land use change modeling. In the long run, this map could also facilitate strategic European policy processes. This approach emulates the decision-making process of local forest owners and managers within the framework of physical, legal, and ecological constraints. Using these constraints, we propose a formal method to calculate the theoretical suitability for different forest management approaches at the square kilometer level across Europe. This theoretical approach acknowledges the variation between localities in their suitability for different management approaches, and allows for scaling to regional trends in forest management. The presented map is a first attempt in that direction, and is awaiting further availability of European-wide information.

Responses to this article can be read online at: http://www.ecologyandsociety.org/issues/responses. php/5149

\section{Acknowledgments:}

This research was funded by the European Commission through the projects EFORWOOD (contract nr FP6-518128-2) and MOTIVE (grant No. 226544), and the BSIK-IC2-project, co-funded by the strategic research programs "Sustainable spatial development of ecosystems, landscapes, seas and regions" and "Climate change" of the former Dutch Ministry of Agriculture, Nature Conservation and Food Quality. Data from the forest inventory of Umbria were provided by Dr. M. Teobaldelli. We thank Dr. Bill Mason, Rach Colling, and two anonymous reviewers for commenting on earlier versions of this manuscript.

\section{LITERATURE CITED}

Beach, R. H., S. K. Pattanayak, J-C Yang, B. C. Murray, and R. C. Abt. 2005. Econometric studies of non-industrial private forest management: a review and synthesis. Forest Policy and Economics 7(3):261-281. http://dx.doi.org/10.1016/S1389-9341 (03)00065-0

Bottcher, H., M. Gusti, P. J. Verkerk, and P. Havlik. 2012. Projection of the EU27 forest sector carbon sink and effects of recent bioenergy policies using two advanced forestry models. Manuscript based on DG ENV tender contract 07.0307/2009/541003/SER/C5. In press.

Brus, D. J., G. M. Hengeveld, D. J. J. Walvoort, P. W. Goedhart, A. H. Heidema, G. J. Nabuurs, and K. Gunia. 2012. Statistical mapping of tree species over Europe. European Journal of Forest Research 131(1):145-157. http://dx.doi. org/10.1007/s10342-011-0513-5

Bugmann H. 2001. A review of forest gap models. Climate Change 51(3-4): 259-305.

Colle, G., F. De Natale, L. Di Cosmo, A. Floris, C. Gagliano, P. Gasparini, A. Paletto, G. Scrinzi, G. Tabacchi, and V. Tosi. 2006. Principali aspetti methodologici delínventario nazionale delle foreste e dei serbatoi forestali dicarbonio Atti del $42^{\circ}$ Corso di Cultura in Ecologia "Stima del carbonio in foresta: metodologie ed aspetti normativi". Università di Padova, Dipartimento Territorio e Sistemi Agro-forestali. San Vito di Cadore (BL), 5-8 Giugno 2006:23-34.

Didion, M., M.-J. Fortin, and A. Fall. 2007. Forest age structure as indicator of boreal forest sustainability under alternative management and fire regimes: a landscape level sensitivity analysis. Ecological Modelling 200:45-58. http:// dx.doi.org/10.1016/j.ecolmodel.2006.07.011

Dirkse, G. M., W. P. Daamen, H. Schoonderwoerd, and J. M. Paasman. 2003. Meetnet Fuctievervulling ${ }_{\text {bos }}$ Het Nederlandse bos in 2001-2002. Expertisecentrum LNV, Ede. 
Duncker, P. S., S. M. Barreiro, G. M. Hengeveld, T. Lind, W. L. Mason, S. Ambrozy, and H. Spiecker. 2012. Classification of forest management approaches: a new conceptual framework and its applicability to European forestry. Ecology and Society 17(4): 51. http://dx.doi.org/10.5751/ES-05262-170451

European Environmental Agency (EEA). 2007. Environmentally compatible bio-energy potential from European forests. http:// biodiversity-chm.eea.europa.eu/information/database/forests/ EEA_Bio_Energy_10-01-2007_low.pdf

European Environmental Agency (EEA). 2008. European forests-ecosystem conditions and sustainable use. European Environment Agency Report nr 3/2008. Copenhagen, Denmark.

Farrell, E. P., E. Führer, D. Ryan, F. Andersson, R. Hüttl, and P. Piussi. 2000. European forest ecosystems: building the future on the legacy of the past. Forest Ecology and Management 132:5-20. http://dx.doi.org/10.1016/S0378-1127 $\underline{(00) 00375-3}$

Food and Agricultural Organization of the United Nations (FAO). 2007. State of the world's forests 2007. Food and Agricultural Organization of the United Nations, Rome, Italy.

Gallaun, H., G. Zanchi, G. J. Nabuurs, G. Hengeveld, M. Schardt, and P. J. Verkerk. 2010. EU-wide maps of growing stock and above-ground biomass in forests based on remote sensing and field measurements. Forest Ecology and Management 260(3): 252-261.

Hasenauer, H. (editor). 2006. Sustainable forest management. Growth models for Europe. Springer, Heidelberg, Germany. http://dx.doi.org/10.1007/3-540-31304-4

Intergovernmental Panel on Climate Change (IPCC). 2007. Mitigation. Contribution of Working Group III to the fourth assessment report of the Intergovernmental Panel on Climate Change. Cambridge University Press, Cambridge, UK.

Ministerial Conference on the Protection of Forests in Europe (MCPFE). 2007. State of Europe's forests 2007. The MCPFE report on sustainable forest management in Europe. MCPFE/ UNECE/FAO, Warsaw, Poland.

Nabuurs, G.J. 2001. European forests in the 21st century: longterm impacts of nature oriented forest management assessed with a large scale scenario model. Research Notes 121. Dissertation. University of Joensuu, Finland. ALTERRA Scientific Contributions 2. Wageningen, The Netherlands.

Nabuurs, G. J., R. Päivinen, A. Pussinen, and M. J. Schelhaas. 2003. European forests until 2050 - a projection of forests and forest management in thirty countries. European Forest Institute Research Report 15. Brill. Leiden, Boston, Kölln.

Paillet, Y., L. Bergès, J. Hjältén, P. Ódor, C. Avon, M. Bernhardt-Römermann, R.-J. Bijlsma, L. de Bruyn, M. Fuhr,
U. Gradin, R. Kanka, L. Lundin, S. Luque, T. Magura, S. Matesanz, I. Mészáros, M.-T. Sebastià, W. Schmidt, T. Standovár, B. Tóthmérész, A. Uotila, F. Valldares, K. Vellak, and R. Virtanen. 2010. Biodiversity differences between managed and unmanaged forests: meta-analysis of species richness in Europe. Conservation Biology 24(1):101-112. http://dx.doi.org/10.1111/j.1523-1739.2009.01399.x

Palahí, M., T. T. Pukkala, J. A. A. Bonet, C. C. Colinas, C. C. R. Fischer, and J. J. R. Martínez de Arago'ón. 2009. Effect of the inclusion of mushroom values on the optimal management of even-aged pine stands of Catalonia. Forest Science 55:503.

Pretzsch, H., R. Grote, B. Reineking, T. Roetzer, and S. Seifert. 2008. Models for forest ecosystem management: a European perspective. Annals of Botany 101(8):1065-1087.

Schelhaas, M. J., J. Eggers, M. Lindner, G. J. Nabuurs, A. Pussinen, R. Päivinen, A. Schuck, P. J. Verkerk, D. C. van der Werf, and S. Zudin. 2007. Model documentation for the European Forest Information Scenario model (EFISCEN 3.1). Wageningen, Alterra, Alterra report 1559, EFI Technical Report 26, Joensuu, Finland.

Schelhaas, M. J., A. Schuck, S. Varis, and S. Zudin. 2003. Database on forest disturbances in Europe (DFDE) - technical description. Internal Report 14. European Forest Institute, Joensuu, Finland.

Schuck, A., J. Van Brusselen, R. Päivinen, T. Häme, P. Kennedy, and S. Folving. 2002. Compilation of a calibrated European forest map derived from NOAA-AVHRR data. Internal Report 13, European Forest Institute, Joensuu, Finland.

Schulp, C. J.E., G. J. Nabuurs, and P. H. Verburg. 2008. Future carbon sequestration in Europe-effects of land use change. Agriculture, Ecosystems and Environment 127(2008):251264. http://dx.doi.org/10.1016/j.agee.2008.04.010

Sterba, H., M. Golser, M. Moser, and K. Schadauer. 2000. A timber harvesting model for Austria. Computers and Electronics in Agriculture 28:133-149. http://dx.doi. org/10.1016/S0168-1699(00)00121-6

Tröltzsch, K., J. Van Brusselen, and A. Schuck. 2009. Spatial occurrence of major tree species groups in Europe derived from multiple data sources. Forest Ecology and Management 257(1):294-302. doi:10.1016/j.foreco.2008.09.012

Tupek, B., G. Zanchi, P. J. Verkerk, G. Churkina, N. Viovy, J. K. Hughes, and M. Lindner. 2010. A comparison of alternative modelling approaches to evaluate the European forest carbon fluxes. Forest Ecology and Management 260 (3):241-251. http://dx.doi.org/10.1016/j.foreco.2010.01.045

UN-ECE. 2005. European forest sector outlook study, main report. ECE/TIM/SP/20. United Nations, Geneva, Switzerland. 
Verburg, P. H., B. Eickhout, and H. van Meij1. 2008. A multiscale, multi-model approach for analyzing the future dynamics of European land use. Annals of Regional Science 42(1):5777. http://dx.doi.org/10.1007/s00168-007-0136-4

Verkerk, H., and M. Lindner. 2008. Report describing the link between external drivers, forest management practices and the main forest externalities. EXIOPOL deliverable report II.4b-1. EXIOPOL Report Series, http://www.feem-project.net/ exiopol/userfiles/file/Cluster\%20II_M18_PU/EXIOPOL_DII.4. b-1_FINAL.pdf. FEEM, Milano, Italy.

Verkerk, H., M. Lindner, P. Anttila, and A. Asikainen. 2010. The realistic supply of biomass from forests. Pages 56-79 inEUwood-final report. Hamburg, Germany.

Zanchi, G., N. Pena, and N. Bird. 2010. The upfront carbon debt of bioenergy. Joannaeum research, Graz. 